\title{
O uso das Tecnologias Educacionais nas escolas públicas durante a pandemia de
}

\section{Covid-19}

\author{
The use of Educational Technologies in public schools during the Covid-19 pandemic \\ El uso de Tecnologías Educativas en las escuelas públicas durante la pandemia Covid-19
}

Recebido: 01/09/2021 | Revisado: 08/09/2021 | Aceito: 27/09/2021 | Publicado: 28/09/2021

\author{
Genival Francisco Costa Júnior \\ ORCID: https://orcid.org/0000-0002-6420-5764 \\ E.E Professor José Ignácio de Sousa, Brasil \\ E-mail: genivalfc@yahoo.com.br
}

\begin{abstract}
Resumo
A crise sanitária provocada pela pandemia de Covid-19 mudou por completo o cenário da educação no país, apresentando-nos uma situação nova e desafiadora, impondo aos profissionais da educação uma rotina de distanciamento que rompeu por completo com o elo entre alunos e professores. Diante desse fato fez-se necessária a implementação de novas práticas pedagógicas voltadas para o ensino remoto e a inserção das tecnologias educacionais que se tornaram instrumentos indispensáveis para o processo de ensino e aprendizagem. O objetivo desse trabalho foi revisar a literatura em busca de artigos que observaram como os professores e alunos têm lidado com as dificuldades e obstáculos advindos da necessidade de implementação do ensino remoto durante o período de pandemia. Como procedimento metodológico adotou-se uma pesquisa bibliográfica baseada no levantamento em artigos científicos disponibilizados por pesquisadores da área da educação na Internet. Dessa forma, evidenciou-se que compreender as necessidades dos estudantes e docentes, possibilitando a todos a acessibilidade às tecnologias educacionais, e auxiliar a comunidade escolar em suas limitações ao utilizar as tecnologias disponibilizadas na rede de ensino, é essencial para reduzir os prejuízos à educação decorrentes da Pandemia.
\end{abstract}

Palavras-chave: Ensino remoto; Tecnologias educacionais; Internet; Covid-19.

\begin{abstract}
The health crisis caused by the Covid-19 pandemic completely changed the education scenario in the country, presenting us a new and challenging situation, imposing on education professionals a routine of distancing that completely broke the link between students and teachers. In view of this fact, it was necessary to implement new pedagogical practices aimed at remote teaching and the insertion of educational technologies that have become indispensable instruments for the teaching and learning process. The objective of this work was to review the literature in search of articles that observed how teachers and students have dealt with the difficulties and obstacles arising from the need to implement remote learning during the pandemic period. As a methodological procedure, a bibliographic research based on a survey of scientific articles made available by researchers in the field of education on the Internet was adopted. Thus, it was evident that understanding the needs of students and teachers, enabling everyone to have access to educational technologies, and helping the school community in its limitations when using the technologies available in the educational network, is essential to reduce the damage to education resulting from the Pandemic.
\end{abstract}

Keywords: Remote teaching; Educational technologies; Internet; Covid-19.

\section{Resumen}

La crisis de salud provocada por la pandemia Covid-19 cambió por completo el escenario educativo en el país, presentándonos una nueva y desafiante situación, imponiendo a los profesionales de la educación una rutina de distanciamiento que rompió por completo el vínculo entre estudiantes y profesores. Ante este hecho, fue necesario implementar nuevas prácticas pedagógicas orientadas a la enseñanza a remota y la inserción de tecnologías educativas que se han convertido en instrumentos indispensables para el proceso de enseñanza y aprendizaje. El objetivo de este trabajo fue revisar la literatura en busca de artículos que observaran cómo profesores y estudiantes han enfrentado las dificultades y obstáculos derivados de la necesidad de implementar el aprendizaje remota durante el período pandémico. Como procedimiento metodológico, se adoptó una investigación bibliográfica basada en una encuesta de artículos científicos puestos a disposición por investigadores en el campo de la educación en Internet. Así, se evidenció que comprender las necesidades de estudiantes y profesores, posibilitar que todos tengan acceso a las tecnologías educativas y ayudar a la comunidad escolar en sus limitaciones al utilizar las tecnologías disponibles en la red educativa, es fundamental para reducir el daño a la educación resultante de la pandemia.

Palabras clave: Enseñanza remota; Tecnologías educativas; Internet; COVID-19. 


\section{Introdução}

O uso da tecnologia para auxiliar no ensino e aprendizagem tem avançado bastante desde que os computadores e a Internet ficaram mais acessíveis a um grande número de estudantes no Brasil. No entanto, o acesso às tecnologias educacionais não está disponível à população na sua totalidade, pois milhares de alunos matriculados no ensino público não conseguem adquirir celulares, smartphones e notebooks, por não terem condições financeiras para comprá-los e se beneficiarem do suporte que estas tecnologias podem propiciar para o ensino, principalmente no período da Pandemia de Covid-19, em 2020 e 2021. Todos os equipamentos tecnológicos citados anteriormente fazem parte das Tecnologias da Informação e Comunicação (TIC). Essas ferramentas já são utilizadas há bastante tempo na modalidade de Educação a Distância EaD). Mendes (2008) define TIC como:

(...) um conjunto de recursos tecnológicos que, quando integrados entre si, proporcionam a automação e/ou a comunicação nos processos existentes nos negócios, no ensino e na pesquisa científica (...).

No período de Pandemia de Covid-19, que tem perdurado por mais de 18 meses, foi instituído o ensino remoto em todas as escolas do Brasil, e o uso dessas tecnologias em prol da educação tornou-se essencial para a continuidade do ensino e da aprendizagem. Diferentemente do ensino presencial, o ensino remoto acontece apenas através do ambiente virtual, e tem como característica principal a transmissão de aulas em tempo real (também chamadas síncronas, ao vivo).

Visando atender aos milhares de estudantes impossibilitados de frequentar as escolas devido a Pandemia, a Secretaria Estadual de Educação de Minas Gerais (SEE) implementou o Regime Especial de Atividades não Presenciais (REANP), por meio da resolução n. ${ }^{\circ}$ 4.310/2020 (Minas Gerais, 2020). A Resolução SEE No 4310/2020:

Dispõe sobre as normas para a oferta de Regime Especial de Atividades Não Presenciais, e institui o Regime Especial de Teletrabalho nas Escolas Estaduais da Rede Pública de Educação Básica e de Educação Profissional, em decorrência da pandemia Coronavírus (COVID-19), para cumprimento da carga horária mínima exigida (Minas Gerais, 2020).

O REANP foi organizado em três eixos, que se constituem como tecnologias vinculadas: (i) o aplicativo Conexão Escola (ii) o Plano de Estudos Tutorados (PET), e (iii) o Programa Se Liga na Educação (Minas Gerais, 2021).

Nesse modelo de ensino, as aulas ocorrem tanto por meio de transmissões ao vivo como também podem ser previamente gravadas, possibilitando aos alunos interação diária com o professor e o acesso ao conteúdo das disciplinas. Neste momento em que o ensino presencial foi substituído pelo ensino remoto, para que sejam evitadas aglomerações e o contágio em massa de estudantes e professores, a interação entre escola e aprendizes passou a acontecer por meio virtual, e as tecnologias educacionais é que passaram a ser a ponte entre professores e alunos. Já no final do primeiro ano de Pandemia, em alguns Estados teve início a modalidade de ensino híbrido com o intuito de retomar as aulas presenciais de forma gradual e segura para toda a comunidade escolar.

De acordo Christensen, Horn e Johnson (2010), o ensino híbrido é definido como um programa de educação formal, que permite ao aluno realizar as atividades propostas, por meio do ensino on-line e presencial, de modo integrado. Ao utilizar essas duas modalidades de ensino fez-se necessário desenvolver meios que possibilitasse a conexão entre professores e alunos. Desse modo, o ano letivo de 2020 foi marcado pelo uso das tecnologias educacionais e esse processo tem se estendido em 2021, embora uma pequena parte da comunidade escolar já venha trabalhando com o ensino híbrido, principalmente a rede escolar privada. No entanto, devido ao compasso lento da campanha de vacinação no Brasil, é certo que o retorno à modalidade de ensino presencial no país ainda leve algum tempo para ocorrer, o que deixa claro que o uso das tecnologias educacionais se mantenha por um tempo indefinido. 
Portanto, tanto professores como aprendizes ainda estão se adequando ao uso dessas tecnologias para que o processo de ensino e aprendizagem não seja prejudicado. De modo que, tornou-se imperativo que, para exercer a docência, os professores transformassem partes de suas casas em salas de aula, utilizando para isso seus computadores, celulares e Internet, para ensinar e auxiliar os alunos na aprendizagem das disciplinas. Para aqueles que já possuíam alguma intimidade com a tecnologia, esse processo mostrou-se bastante árduo; para os docentes que não se interessavam pelo uso das tecnologias no âmbito escolar o uso da tecnologia apresentou-se como algo desafiador. Os professores da rede pública de Minas Gerais iniciaram o ano letivo de 2021 participando de um curso de capacitação online para o uso das tecnologias educacionais, já que em 2020 não houve essa possibilidade, fator que gerou bastante estresse e acúmulo de trabalhos extras para os docentes.

O objetivo desse estudo foi investigar e discutir as tecnologias educacionais utilizadas no Período da Pandemia para o ensino durante o ano letivo de 2020 no Estado de Minas Gerais de acordo com a literatura disponível até meados de 2021.

\section{Metodologia de Pesquisa}

Utilizou-se como metodologia uma pesquisa de natureza qualitativa, por meio da pesquisa bibliográfica. De acordo com Severino (2007, p. 122), a partir do:

[...] registro disponível, decorrente de pesquisas anteriores, em documentos impressos, como livros, artigos, teses etc. Utilizam-se dados de categorias teóricas já trabalhadas por outros pesquisadores e devidamente registrados. Os textos tornam-se fontes dos temas a serem pesquisados. O pesquisador trabalha a partir de contribuições dos autores dos estudos analíticos constantes dos textos

\section{Procedimentos metodológicos}

A coleta dos dados para o embasamento da pesquisa se deu por meio de buscas na Internet por artigos, teses e dissertações, de autores que pesquisaram as tecnologias educacionais e seus usos no contexto de Pandemia, no ano de 2020 e 2021.

\section{O uso das Tecnologias no Ensino Público no Contexto da Pandemia}

Para garantir a continuidade das aulas no período de Pandemia foi necessário que o governo do Estado de Minas Gerais adotasse medidas que viabilizassem o ensino remoto. Primeiramente foi criado o Conexão Escola, aplicativo desenvolvido pelo governo para auxiliar estudantes e professores a se conectarem. Toda a comunidade escolar fez o download do aplicativo e alunos e professores ficaram conectados durante os horários de aula. Além do aplicativo citado, estão sendo utilizadas as ferramentas da plataforma Google tais como: Google Meet, que é utilizada para aulas online e também para reuniões entre professores e equipes pedagógicas das escolas. No caso das ferramentas Google Forms e Google Classroom, estas são utilizadas para postagens de atividades, aulas gravadas, vídeos e também para correções de tarefas e interação por escrito entre aprendizes e mestres. O aplicativo de mensagens WhatsApp, por ser gratuito, tornou-se um grande aliado de professores e alunos, já que permite a troca de mensagens instantâneas via celular, possibilitando que os professores sanem as dúvidas dos estudantes a qualquer momento.

O WhatsApp Messenger é um aplicativo de mensagens para celulares (múltiplas plataformas) também disponível para web, que permite a troca de mensagens de texto, imagens, vídeos, áudios e documentos de forma gratuita, por meio de uma conexão de internet. Além das mensagens básicas, os usuários do aplicativo têm a opção de criar grupos para estender a comunicação com mais pessoas (Paiva, et al., 2016, p. 752). 
Outra utilidade do WhatsApp é que também é utilizado pelas escolas como um canal de contato com toda a comunidade escolar através de grupos das turmas organizados com intuito de informar e orientar professores e alunos. Desse modo, é imprescindível que tanto os professores como alunos tenham acesso à Internet, acesso a celulares e computadores (notebooks) que sejam capazes de propiciar a interação necessária para a continuidade do processo de ensino e aprendizagem. Segundo Brasil (2021):

A pesquisa do Instituto DataSenado mostra que a diferença entre a educação na rede pública e na rede privada também se revela no acesso dos alunos à internet. Dos lares cujos estudantes estão tendo aulas remotas na rede pública, 26\% não possuem internet. Já na rede privada, o percentual cai para 4\%. Ainda segundo os resultados, o celular $(64 \%)$ e o computador $(24 \%)$ são os equipamentos mais utilizados para acessar os materiais de estudo.

Contudo, o acesso a estes equipamentos é vital para que a comunidade escolar possa desenvolver as modalidades de ensino remoto e híbrido de forma eficiente, e sem prejuízos à clientela das instituições de ensino. É necessário mencionar que todo o aparato descrito e as plataformas utilizadas no contexto de ensino remoto não funcionam sem uma rede de Internet, o que torna o acesso a esta rede parte indispensável para o uso das tecnologias educacionais. Segundo informações do CENPEC Educação, coletadas da TIC Educação 2019, “1 milhão de estudantes de escolas urbanas de Ensino Fundamental e Ensino Médio acessam a Internet exclusivamente pelo celular - sendo que 96\% deles estão nas escolas públicas municipais e estaduais" (Abe, 2020).

Para além do acesso à rede de Internet, e a equipamentos como computadores e celulares, é necessário investir na formação dos professores para lidar com essas tecnologias, pois muitos professores em exercício na educação pública não são letrados digitalmente. Freitas e Costa (2010) conceituam Letramento Digital como:

“O conjunto de competências necessárias para que o indivíduo entenda e use a informação de maneira crítica e estratégica, em formatos múltiplos, vinda de variadas fontes e apresentada por meio do computador-internet, sendo capaz de atingir seus objetivos, muitas vezes compartilhados social e culturalmente". (Freitas; Costa, 2010, p. 339).

Todavia para que os docentes adquiram as competências necessárias para utilizar as tecnologias da educação em sala de aula é preciso que estes tenham a sua disposição aprendizados por meio de cursos que os habilitem a operar e utilizar as tecnologias educacionais disponíveis para que se tornem digitalmente letrados.

A formação do professor deve ocorrer de forma permanente e para a vida toda. Sempre surgirão novos recursos, novas tecnologias e novas estratégias de ensino e aprendizagem. O professor precisa ser um pesquisador permanente, que busca novas formas de ensinar e apoiar alunos em seu processo de aprendizagem (Jordão, 2009, p.12).

Ao buscar conhecimentos que os capacitem a lidar com o aparato tecnológico disponibilizado pelo governo nas plataformas digitais e na escola, os professores estão investindo não somente em sua formação, mas também no processo de aprendizagem do aluno através do próprio exemplo de que aprender deve ser uma tarefa contínua e não está limitada apenas ao ambiente escolar.

\section{Os Desafios e Dificuldades de Professores e Alunos em Utilizar as Tecnologias Educacionais}

Há alguns anos somos auxiliados pela tecnologia há todo momento. Os equipamentos tecnológicos utilizados na comunicação tornaram-se indispensáveis no cotidiano de milhares de pessoas. No entanto, a maior parte da população não utiliza celulares, notebooks e smartphones como ferramentas de trabalho e sim como equipamentos para interação com outras pessoas e diversão. Conforme Prado, 2005: 
Embora a tecnologia seja um elemento da cultura bastante expressivo, ela precisa ser devidamente compreendida em termos das implicações do seu uso no processo de ensino e aprendizagem.

Para a maioria dos professores e alunos da rede pública, essa realidade não era diferente, até a chegada da Pandemia de Covid-19 e da implementação da modalidade de ensino remoto e híbrido na rede pública. Um grande desafio para que as TICS sejam utilizadas no processo de ensino e a aprendizagem diz respeito às dificuldades dos professores em utilizar essas ferramentas. Além disso, muitos não se dispõem a aprender a como fazer uso das mesmas, gerando dessa forma uma verdadeira aversão a inserção da tecnologia em sala de aula. Como aponta Sahb (2016, p. 6):

A falta de recursos, de infraestrutura, o despreparo dos professores e da equipe pedagógica, os materiais que chegam à escola por imposição e não por escolha dos professores, a quantidade de material inadequada ao porte do colégio, estão entre os principais. Tais fatores interferem consideravelmente na disposição dos educadores para a utilização das inovações, como se fosse possível ficar indiferente à influência que elas exercem sobre as pessoas.

No que concerne aos alunos, o cenário não é muito diferente. Eles tiveram sua rotina escolar transformada com a chegada da Pandemia da Covid-19 e a entrada do ensino remoto em suas vidas. Tanto estudantes quanto professores não sabiam utilizar todas as ferramentas da Google disponibilizadas pela Plataforma Conexão Escola, e o que aconteceu foi um grande desgaste para toda a comunidade escolar. A competência 5 da Base Nacional Comum Curricular (BNCC) de 2018 (Brasil, 2018) versa sobre o uso crítico e responsável das tecnologias digitais, destacando a necessidade do desenvolvimento por parte de professores e alunos das habilidades para o uso das TICS, destaca:

Compreender, utilizar e criar tecnologias digitais de informação e comunicação de forma crítica, significativa, reflexiva e ética nas diversas práticas sociais (incluindo as escolares) para se comunicar, acessar e disseminar informações, produzir conhecimentos, resolver problemas e exercer protagonismo e autoria na vida pessoal e coletiva. (Brasil, 2018)

No entanto, a maioria dos docentes e estudantes não dispõe de condições econômicas para ter acesso a esses equipamentos e nem mesmo oportunidade de buscar o conhecimento necessário para fazer o uso das tecnologias da educação nesse momento, no qual o ensino remoto tornou-se a única possibilidade para milhões de brasileiros.

As dificuldades enfrentadas pela comunidade escolar em 2020 continuam no ano de 2021, não apresentando um quadro muito diferente do ano letivo anterior. Pais, professores e alunos fazem o que podem para que o processo de ensino e aprendizagem tenha continuidade. De acordo com Moran (2006, p. 32), “é importante diversificar as formas de dar aula, de realizar atividades e de avaliar". Contudo o ensino realizado por meio de plataformas on-line, recursos digitais, distribuição de Plano de Estudo Tutorado (PET) impressos para os alunos que não têm acesso à Internet, e as aulas transmitidas por meio da TV aberta, são neste período de pandemia a aposta das secretarias de educação para levar o ensino à comunidade escolar em sua totalidade. Embora todos os profissionais da educação tenham se esforçado para manter a proximidade entre professores e alunos através de encontros virtuais, chats com as turmas para tirar dúvidas através do aplicativo WhatsApp e aulas on-line via Google Meet, a Pandemia de Covid-19 impôs aos estudantes e professores um distanciamento extremamente nocivo a ambas as partes através do Ensino Remoto e Emergencial (ERE), inviabilizando ainda mais o acesso ao frágil sistema público de educação do país. Para Behar (2020):

O ensino é considerado remoto porque os professores e alunos estão impedidos por decreto de frequentarem instituições educacionais para evitar a disseminação do vírus. É emergencial por que do dia para noite o planejamento pedagógico para o ano letivo de 2020 teve que ser engavetado (Behar, 2020). 
Dessa forma, professores e alunos têm vivenciado uma rotina bastante estressante para dar continuidade às tarefas de ensinar e aprender. Para os docentes habituados ao cotidiano das escolas, o que resta é uma grande quantidade de tarefas a cumprir e a cobrança da sociedade pelo retorno das aulas presenciais. No que tange aos alunos, estes passam por constantes desafios para lidar com a realidade do ensino remoto, que vão desde a falta de acesso à Internet até as dificuldades de usar os aplicativos nos quais as atividades são compartilhadas para resolução. Diante dessa perspectiva, pode-se destacar que:

A tecnologia em rede e móvel e as competências digitais são componentes fundamentais de uma educação plena. Um aluno não conectado e sem domínio digital perde importantes chances de se informar, de acessar materiais muito ricos disponíveis, de se comunicar, de se tornar visível para os demais, de publicar suas ideias e de aumentar sua empregabilidade futura (Moran, 2018, p. 13).

Esta falta de domínio resulta em atrasos nas entregas das atividades e corrobora para que uma grande quantidade de estudantes desista de realizar as tarefas disponibilizadas na plataforma Conexão Escola.

O desinteresse provocado pelas dificuldades de acesso, e de conhecimento por parte dos estudantes em utilizar as ferramentas tecnológicas, têm sido motivo de inúmeras discussões entre professores e supervisores nas reuniões de módulos e pelas equipes pedagógicas das escolas, para que sejam encontradas soluções para motivar os aprendizes a realizar as atividades propostas. Portanto, foi adicionada ao trabalho dos professores a tarefa de auxiliar os alunos a utilizar as tecnologias disponíveis para a realização das tarefas postadas nas plataformas digitais o que resulta em aprendizado para ambos. Costa (2003), afirma que o uso das TIC promove mudanças nas salas de aulas e no trabalho docente:

O uso dessas tecnologias é importante não apenas para benefício do professor em termos do seu próprio desenvolvimento profissional, mas, sobretudo, para poder utilizá-la com seus próprios alunos, proporcionando-lhes situações de aprendizagens inovadoras, mais interessantes e mais próximas da realidade envolvente (p. 01).

Os professores são constantemente cobrados a incentivar de todas as formas os alunos para que os mesmos se mantenham interessados e produtivos através de intervenções pedagógicas, sábados letivos e diversas ações que são impostas pelo Estado. Todas essas exigências advindas da implementação do ensino remoto sobrecarregam os docentes sobremaneira, afetando diretamente a qualidade do ensino e da prática do professor. Demo (2008, p.134) ressalta:

Temos que cuidar do professor, pois todas as mudanças só entram bem na escola se entrarem pelo professor, ele é a figura fundamental. Não há como substituir o professor. Ele é a tecnologia das tecnologias, e deve se portar como tal. (Apud Andrade, p.16)

O quadro atual que se apresenta para a comunidade escolar de Minas Gerais revela-se muitas vezes confuso e tenso diante de tantas tentativas frustradas de solucionar os problemas advindos da implementação do ensino remoto. As soluções buscadas pelo governo para dar continuidade ao ensino são bastante eficazes no papel. No entanto, em um Estado com uma população bastante diversificada e com diferentes realidades econômicas e sociais, distribuídas em 853 municípios, todas essas inovações têm levado a comunidade escolar apenas a adaptar-se ao novo sem ter como lograr êxito em um pequeno espaço de tempo. Kenski (2009, p.103) afirma que:

um dos grandes desafios que os professores brasileiros enfrentam está na necessidade de saber lidar pedagogicamente com alunos e situações extremas: dos alunos que já possuem conhecimentos avançados e acesso pleno às últimas inovações tecnológicas aos que se encontram em plena exclusão tecnológica; das instituições de ensino equipadas com mais modernas tecnologias digitais aos espaços educacionais precários e com recursos mínimos para o exercício da função docente. O desafio maior, no entanto, ainda se encontra na própria formação profissional para enfrentar esses e tantos outros problemas. 
Com o propósito de atender a comunidade escolar e solucionar as dificuldades na utilização do aplicativo Conexão Escola e das ferramentas Google a Secretaria Estadual de Educação (SEE) disponibilizou cursos de formação como o Google for Education: recursos e possibilidades, elaborado pela equipe da Escola de Formação e Desenvolvimento Profissional e de Educadores e dos Núcleos de Tecnologia Educacional das Superintendências Regionais de Ensino, que tem como função capacitar os profissionais da educação para utilizar ferramentas da tecnologia da comunicação para ensinar, aprender e se conectar. De modo que ao concluir este curso os professores se sintam mais capacitados a auxiliar os alunos em suas dificuldades e ensiná-los a lidar com a realidade do ensino remoto por meio do Conexão Escola (Figura 1).

O aplicativo Conexão Escola 2.0 utilizado por professores e alunos desde o início do ano letivo de 202em se revelado uma fonte de frustrações, embora seja de simples operação, milhares de alunos não acessam o aplicativo no horário das aulas, e ao contrário de sua primeira versão, não existem trocas de mensagens em tempo real como no aplicativo WhatsApp. Desse modo, quando os estudantes querem se comunicar para sanar dúvidas sobre a resolução dos PET com os professores, preferem fazê-lo pelo aplicativo de mensagens ou por e-mail, isto é, quando há celulares disponíveis em suas casas, e não é raro que os docentes sejam contatados aos sábados ou domingos, pois nesses dias os pais estão em casa, o que possibilita aos estudantes o acesso aos aparelhos.

Figura 1 - Aplicativo Conexão Escola 2.0.

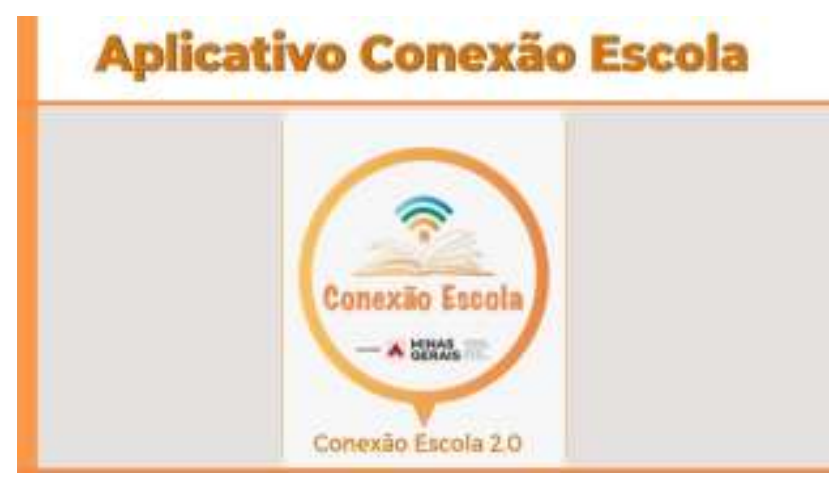

Fonte: https://www2.educacao.mg.gov.br/component/gmg/story/11284-aplicativo-conexao-escola-2-0-ja-esta-disponivel-para-professores-ealunos-da-rede-estadual-de-minas-gerais.

Diante de todo aparato ofertado para que o ensino e a aprendizagem ocorram em Minas Gerais, o que se vê na comunidade escolar é uma batalha entre pais, professores e Estado, e para este último o que parece importar são os números de aprovados. Almeida (2001) destaca que é preciso integrar os recursos tecnológicos e midiáticos de forma significativa no processo ensino e aprendizagem. Contudo o que pode ser observado, é que são as diferentes realidades de cada município e cada família que tem pautado o andamento do ensino remoto no contexto da Pandemia de Covid-19.

\section{Considerações Finais}

Ao implementar o ensino remoto por meio do REANP e da plataforma Conexão Escola utilizando as TICS como ferramentas para o ensino e a aprendizagem na rede pública de ensino de Minas Gerais, o governo do Estado não levou em consideração as diferentes realidades dos estudantes e professores. Nós professores nos vemos às voltas com a baixa adesão dos alunos ao ensino remoto devido à falta de interesse dos mesmos em participar de aulas online e em buscar até mesmo ajuda dos professores para resolver as tarefas dos PET.

As exigências, tais como: realizar busca ativa, entrar em contato com os pais e preparar atividades que estimulem os alunos a se interessarem pelos estudos é constante na rotina imposta pelo ensino remoto. 
Embora haja esforço tanto da parte dos docentes quanto dos alunos, há uma grande frustração em se preparar aulas e outras atividades para um número reduzido de participantes. Durante o primeiro ano da Pandemia muitos estudantes dos anos finais do ensino fundamental deixaram de realizar as atividades e abandonaram a escola, alegando não ter acesso a celulares e computadores, e conexão de internet para se conectarem ao aplicativo Conexão Escola. Estes fatores que têm prejudicado bastante o êxito dessa modalidade de ensino.

Diante desse cenário a resposta dos pais ou responsáveis ao ensino remoto também não é das mais animadoras, muitos não conseguem auxiliar os filhos com os estudos por falta de conhecimento para acessar o aplicativo, e dessa forma deixam de acompanhá-los durante a realização das atividades. Desse modo, o processo de ensino aprendizagem via ensino remoto exige muito empenho e dedicação de estudantes e professores, e de modo algum tem alcançado as metas exigidas pelo Estado. Não é raro assistir discussões entre professores e supervisores em reuniões online sobre a utilização das mídias e intervenções pedagógicas questionáveis, propostas pela SEE, para que se alcance as metas esperadas pelo governo. Portanto, o uso das tecnologias educacionais diante da crise sanitária provocada pela Pandemia de Covid-19, deve levar em consideração as diferenças sociais e econômicas da sociedade e da comunidade escolar para que o uso dessas tecnologias seja eficaz e inclua todos os personagens que integram o contexto educacional. O que importa é compreender as necessidades dos estudantes e docentes, possibilitar a todos a acessibilidade a equipamentos, auxiliar a comunidade escolar em suas limitações ao utilizar as tecnologias disponibilizadas na rede de ensino, para que se reduza ao máximo os prejuízos advindos das mudanças no processo de ensino e aprendizagem durante o período de Pandemia. Este estudo visa contribuir com outros pesquisadores em seus trabalhos futuros sobre os impactos do uso das tecnologias digitais para o ensino e aprendizagem (impactos positivos e negativos) e para propostas de estudos que versem sobre as contribuições das tecnologias para o ensino e a aprendizagem durante a Pandemia de Covid-19, tendo como foco tanto os alunos quanto os professores.

\section{Referências}

Abe, S. K. (2020). Panorama do uso de Internet e tecnologias pela comunidade escolar brasileira. CENPEC Educação. https://www.cenpec.org.br/noticias/panorama-do-uso-de-internet-e-tecnologias-pela-comunidade-escolar-brasileira.

Andrade, A. P. R. de. Uso das tecnologias na educação: computador e internet. (monografia) Universidade Estadual de Goiás. Brasília, 2011.

Almeida, M. E. B. de. Educação, projetos, tecnologia e conhecimento. PROEM, 2001. 63p.

Behar, P. A. (2020). O Ensino Remoto Emergencial e a Educação a Distância. UFRGS.

Brasil. Ministério da Educação. (2018). Base Nacional Comum Curricular. Educação é a base, Brasília, Ministério da Educação.

Brasil. (2021). Senado notícias. DataSenado: quase 20 milhões de alunos deixaram de ter aulas durante pandemia. Brasília: Agência Senado. https://www12.senado.leg.br/noticias/materias/2020/08/12/datasenado-quase-20-milhoes-de-alunos-deixaram-de-ter-aulas-durante-

pandemia/\#conteudoPrincipal

Costa, F. A. Ensinar e aprender com tecnologias na formação inicial de professores. In: Colóquio da AFIRSE, 12., 2003, Lisboa. Atas[...] Lisboa, AFIRSE Portugal e Instituto de Educação daUniversidade de Lisboa, p. 1-14.

Christensen, C. M.; Horn, M. B., \& Johnson, C. W. Disrupting class: how disruptive innovation will change the way the world learns. (2a ed.), McGraw-Hill.

Freitas, M. T. A.; Costa, S. R. Leitura e escrita de adolescentes na Internet e na escola. (2a ed.), Autêntica.

Jordão, T. C. Formação de educadores: a formação do professor para a educação em um mundo digital. In: Tecnologias digitais na educação. MEC.

Kenski, V. M. Educação e tecnologias: o novo ritmo da informação. (5a ed.), Papirus. 141p.

Mendes, A. TIC - Muita gente está comentando, mas você sabe o que é? Portal iMaster.

Minas Gerais. Secretaria de Estado de Educação. Regime de estudo não presencial - ensino fundamental e ensino médio. SEE/MG, 2021 https://estudeemcasa.educacao.mg.gov.br/inicio.

Minas Gerais. Secretaria de Estado de Educação. Resolução SEE N4.310/2020. SEE/MG,2020Disponívelem:htt ps://www2.educacao.mg.gov.br/images/documentos/Resolucao\%20SEE_N__4310.pdf. 
Research, Society and Development, v. 10, n. 12, e503101220096, 2021

(CC BY 4.0) | ISSN 2525-3409 | DOI: http://dx.doi.org/10.33448/rsd-v10i12.20096

Moran, J. Metodologias ativas para uma aprendizagem mais profunda. In: Bacich, L.; Moran, J. Metodologias ativas para uma educação inovadora: uma abordagem teórico-prática. Penso.

Moran, J. M. Ensino e aprendizagem inovadores com tecnologias audivisuais e telemáticas. In: Moran, J. M. 1; Masetto, M. T.; Behrens, M. A. Novas tecnologias e mediação pedagógica. (12a ed.), Papirus.11-66.

Paiva, L. F. de; Ferreira, A. C. C.; Corlett, E. F. A utilização do WhatsApp como ferramenta de comunicação didático-pedagógica no ensino superior. In: V Congresso Brasileiro de Informática na Educação. Anais dos Workshops [...] (CBIE 2016). 751-760

Prado, M. E. B. B. Pedagogia de projetos: fundamentos e implicações. In: Almeida, Maria Elizabeth Bianconcini de; MORAN, José Manuel (Org.). Integração das tecnologias na educação. Brasília: Ministério da Educação/SEED/TV Escola/Salto para o Futuro, 2005. cap. 1, artigo 1.1, 12-17.

Sahb, W. F. Tecnologias Digitais da Informação e Comunicação e o processo de expansão e integração da educação superior no MERCOSUL. $2016.185 \mathrm{f}$. Tese (Doutorado em Educação) - Pontifícia Universidade Católica de São Paulo, São Paulo, 2016.

Severino, A. J. Metodologia do Trabalho Científico. Cortez. 